Tinbergen Institute Discussion Paper
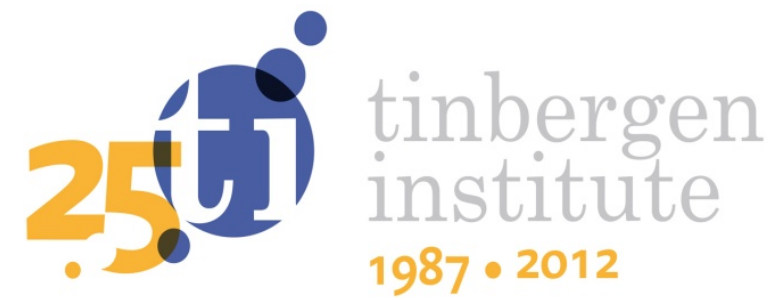

\title{
On Revenue Recycling and the Welfare Effects of Second-Best Congestion Pricing in a Monocentric City
}

loannis Tikoudis

Erik T. Verhoef

Jos N. van Ommeren 
Tinbergen Institute is the graduate school and research institute in economics of Erasmus University Rotterdam, the University of Amsterdam and VU University Amsterdam.

More TI discussion papers can be downloaded at http://www.tinbergen.nl

Tinbergen Institute has two locations:

Tinbergen Institute Amsterdam

Gustav Mahlerplein 117

1082 MS Amsterdam

The Netherlands

Tel.: +31(0)205251600

Tinbergen Institute Rotterdam

Burg. Oudlaan 50

3062 PA Rotterdam

The Netherlands

Tel.: +31(0)10 4088900

Fax: $+31(0) 104089031$

Duisenberg school of finance is a collaboration of the Dutch financial sector and universities, with the ambition to support innovative research and offer top quality academic education in core areas of finance.

DSF research papers can be downloaded at: http://www.dsf.nl/

Duisenberg school of finance

Gustav Mahlerplein 117

1082 MS Amsterdam

The Netherlands

Tel.: +31(0)20 5258579 


\title{
On revenue recycling and the welfare effects of second-best congestion pricing in a monocentric city
}

\author{
Ioannis Tikoudis*, Erik T. Verhoef, Jos N. van Ommeren \\ Department of Spatial Economics, VU University Amsterdam, \\ De Boelelaan 1105, 1081HV Amsterdam, \\ the Netherlands
}

7 February 2013

\begin{abstract}
This paper explores the interactions between congestion pricing and a tax-distorted labor market within a monocentric urban equilibrium model. We compute the efficiency gains of various second-best policies, i.e. combinations of toll schemes and revenue recycling programs, with a predetermined level of public revenue. We find that $35 \%$ of the space-varying road tax does not reflect marginal external congestion costs, but rather functions as a Ramsey-Mirrlees tax, i.e. an efficiency enhancing mechanism allowing space differentiation of the labor tax. Such a space-varying tax adds a quite different motivation to road pricing, since it can produce large welfare gains even in the absence of congestion. We show that both a cordon toll and a flat kilometer tax achieve over $80 \%$ of these gains when combined with specific types of revenue recycling, such as labor tax cuts or public transport subsidies. Sensitivity analysis shows that the optimal type of revenue recycling depends on the level of inefficiency in the provision of public transport prior to the introduction of congestion pricing.
\end{abstract}

Keywords: Second-best road pricing, revenue recycling, monocentric city

JEL classification: R41, R48, H23, H76, J20, R13, R14

*Tel: +31 205982936, e-mail: i.tikoudis@vu.nl 


\section{Introduction}

A substantial part of the second-best road pricing literature is concerned with the simultaneous presence of various distortions and externalities within the transport system. For instance, unpriced alternative routes have been investigated by Verhoef et al. (1996) and Small and Yan (2001). Calthrop et al. (2000) examine policies which combine road and parking charges in a framework with inefficient parking provision. Parry and Bento (2002) focus on pollution, accidents and suboptimal public transport pricing. Relevant distortions outside the transport system which may arise from the taxation of labor income and various regulations in the housing market ${ }^{1}$ will also affect second-best transport policies.

This paper focuses on the interaction between urban road pricing and a distorted labor market. Labor taxation reduces labor supply, and therefore the level of congestion externalities in the transport system. With a preexisting tax on labor income, the traffic level in an untolled equilibrium might already lie below the optimum with the generalized private cost of a commuting trip falling short of its marginal social cost (Parry and Bento, 2001). Then, any policy intervention that introduces road tolls but leaves the labor tax unaffected is expected to produce losses in social welfare.

Despite its obvious importance, this research topic has received limited attention in the transport economics literature, although similar questions have spawned several contributions in the literature of environmental economics (see, for example, Goulder, 1995a). An exception is the paper by Parry and Bento (2001), which indicates a clear recommendation for road pricing in the case of a preexisting labor tax: ${ }^{2}$ in order to increase welfare, road toll revenues must be used to reduce the distortionary tax. However, in that paper, as in a later contribution aiming to investigate critical distortions within the transport system (Parry and Bento, 2002), commuting distance is assumed to be exogenous. Therefore, commuters react to the introduction of a road tax only by adjusting their labor supply, not their commuting distance. While this assumption might be realistic in the short run, one might wonder to what extent the above policy recommendation is valid in the long run, i.e. as commuters are able to relocate.

More important, the lack of a spatial dimension implies that questions involving the differentiation of road taxes over space, and by travel distance, cannot be studied. This prevents the evaluation of second-best congestion pricing schemes such as the cordon toll (Mun et al. 2003; 2005) or a flat kilometer tax (Sullivan, 1983) which are more realistic in practice, but deviate from the first-best. Finally, suboptimal pricing in public transport is ignored. Therefore, the model may understate the welfare gains of policies which use the road toll revenue to subsidize the providers of public transport that operate with increasing returns to density.

In this paper, we focus on a monocentric city model in which household location is endogenous and both residential density and labor supply vary over space. ${ }^{3}$ We combine the insights of the non-spatial labor supply model by Parry and Bento (2001) with the monocentric city model by Verhoef (2005). The aim is to identify the optimal policy, i.e. a combination of a road toll scheme and a revenue recycling

\footnotetext{
${ }^{1}$ These comprise rent control and density regulations (e.g. height restrictions), which may result in a suboptimal allocation of space across economic agents and activities (Glaeser and Luttmer, 2003). Road pricing affects the private and social benefits and costs of land use. Therefore, it can indirectly alter the magnitude of welfare losses in a distorted land/housing market.

${ }^{2}$ For a generic investigation of marginal tax reforms, see Mayeres and Proost (2001).

${ }^{3}$ Throughout the paper, we assume that the labor market is competitive. For the impacts of congestion tolls in a wage bargaining model, see De Borger (2009).
} 
program, taking into account the spatial equilibrium impacts of transport policies both with and without the presence of a suboptimally priced public transport alternative. ${ }^{4}$

The urban equilibrium model introduced in the following section allows city size to vary endogenously as in Verhoef (2005). To facilitate comparability with earlier work, we calibrate its parameters in line with the stylized facts proposed by Parry and Bento (2001) and Verhoef (2005). We compare the welfare gains (or losses) for a range of urban toll schemes and revenue recycling programs. The welfare changes are reported in a relative manner, for instance as in Parry (2002), as well as in absolute monetary terms, by computing the compensating variations of the representative household. Since the results are likely to be sensitive to some of the models parameters, we perform sensitivity analyses with respect to a number of key characteristics: i) the initial level of labor tax, ii) the elasticity of substitution in consumption and iii) the road technology parameters.

One of the main conclusions of the paper is that a space-varying road tax is not desirable exclusively as a congestion management policy: with a tax-distorted labor market it may be welfare improving even in the absence of congestion. One of the reasons is that the elasticity of labor supply exhibits variation over space, while the traditional labor tax is independent of residential location. Thus, a space-varying road tax might improve the performance of an inefficient labor tax system by functioning as a spatial correction of a suboptimal labor tax, allowing it to vary with the elasticity of labor supply.

This spatial differentiation of taxes is in line with the standard Ramsey rule for minimizing the distortionary impacts of taxes used to raise revenues. Our spatial setting, however, reveals a second reason to differentiate taxes by residential location. This concerns the Mirrlees rule, which states that taxes should be lower where the marginal utility of income is higher. In our model, and probably in other spatial configurations, these two arguments appear to work in opposite direction. Labor supply becomes less elastic with commuting distance, as effective labor supply falls, while the marginal utility of monetary income rises, as monetary income falls too. ${ }^{5}$ As a result, the Ramsey-Mirrlees component, defined as the deviation of the optimal road tax from the marginal external cost of congestion, can portray complex, even non-monotonic patterns over space.

To juxtapose labor tax cuts against public transport subsidies, we expand the base model to account for a public transit alternative, which operates with fixed costs. The numerical results show that the optimal type of revenue recycling depends on the initial level of inefficiency in the public transport. For cities served by unsubsidized operators with significant fixed costs, it is optimal to return the road toll revenue in the form of a public transport subsidy, contrary to the results by Parry and Bento (2001).

The structure of the paper is as follows. Section 2 introduces the analytical model in its general form. Section 3 presents the calibration, policy implications and sensitivity analysis in the unimodal framework. Section 4 expands the analysis in a bimodal setting. Section 5 summarizes and concludes.

\footnotetext{
${ }^{4}$ The present paper focuses on the efficiency gains of road pricing for a representative household in a monocentric city. Although revenue recycling is closely related to the various equity considerations of road pricing (Langmyhr, 1997), the distribution of the total gains among heterogeneous households in the context of a monocentric city is another future research challenge. See Ramjerdi et al. (2008) for an empirical approach of this issue.

${ }^{5}$ Note that the latter pattern may be reversed when income heterogeneity is introduced, with higher incomes locating further from the CBD (Brueckner et al., 1999).
} 


\section{Model}

\subsection{Households}

Consumption and labor supply are derived from the utility maximization problem of a representative household, which can be located anywhere within a linear monocentric city, i.e. a city with a single central business district (CBD). Household location is, therefore, a point $z$ which belongs to the open interval $\left(0, z^{*}\right)$, where $z^{*}$ is the distance between the CBD and the endogenously determined city fringe. For a given residential location, $z$, the household maximizes the CES utility function: ${ }^{6}$

$$
U_{z}=\left[\left(\delta_{y} y_{z}\right)^{\rho}+\left(\delta_{s} s_{z}\right)^{\rho}+\left(\delta_{f} T_{F z}\right)^{\rho}\right]^{\frac{1}{\rho}},
$$

where the parameters $\delta_{y}, \delta_{s}$ and $\delta_{f}$ correspond to the consumption of a composite good, $y_{z}$, housing space, $s_{Z}$, and leisure time, $T_{F Z}$, and $\rho$ is the scale parameter that determines the elasticity of substitution, $\sigma$, via $\sigma=1 /(1-\rho)$. The total time endowment, $T$, is spent on commuting, $T_{C Z}$, working, $T_{L Z}$, and leisure, $T_{F z}$ :

$$
T=T_{C Z}+T_{L z}+T_{F z}
$$

Labor supply is inelastic throughout a working day, thus the working day is of fixed duration, $t_{L}$. Every trip to work requires $t_{z}$ units of time. For $D_{W z}$ working days the time constraint becomes:

$$
T=D_{W z} t_{z}+D_{W z} t_{L}+T_{F z}
$$

Normalizing the duration of the working day, $t_{L}$, to 1 , the above constraint becomes:

$$
T=D_{W z}\left(1+t_{z}\right)+T_{F z} \Leftrightarrow D_{W z}=\frac{T-T_{F z}}{1+t_{z}} .
$$

The net wage per working day is defined as the difference between wage, $w$, the labor tax, $\tau_{L}$, and the road toll for the full commuting trip from $z$ to the CBD, $\tau_{R z}$ (which is a function of $z$ ). The full income of the household at distance $z, M_{z}$, is the maximum income which can be realized when leisure time is zero. That is:

$$
M_{z}=B+\frac{\left(w-\tau_{L}-\tau_{R z}\right)}{1+t_{z}} T
$$

where $B$ denotes a lump-sum transfer from the government to the household, independent of its location. This full income can be used to buy back leisure at its shadow price, $\left(w-\tau_{L}-\tau_{R z}\right) /\left(1+t_{z}\right)$, and for the consumption of the composite good and residential space. The budget constraint can then be written as:

$$
B+\frac{\left(w-\tau_{L}-\tau_{R z}\right)}{1+t_{z}} T=\frac{\left(w-\tau_{L}-\tau_{R z}\right)}{1+t_{z}} l_{z}+p y_{z}+r_{z} s_{z}
$$

\footnotetext{
${ }^{6}$ We use a Constant Elasticity of Substitution function to avoid behavioral restrictions imposed by a Cobb-Douglas specification, which implies a unitary elasticity of substitution.
} 
where $p$ is the price of the composite good and $r_{z}$ the rental price per unit of space at location $z$. Maximizing (1) subject to (6), and defining $\chi=\rho /(\rho-1)$ yields the Marshallian demand functions for the composite good, space and leisure time respectively, which depend on $z$ :

$$
\begin{aligned}
& y_{z}^{*}=M_{z} \frac{\left(p / \delta_{y}^{\rho}\right)^{-\sigma}}{\left(p / \delta_{y}\right)^{\chi}+\left(r_{z} / \delta_{s}\right)^{\chi}+\left[\frac{w-\tau_{L}-\tau_{R z}}{\delta_{f}\left(1+t_{z}\right)}\right]^{x}}, \\
& s_{z}^{*}=M_{z} \frac{\left(r_{z} / \delta_{s}^{\rho}\right)^{-\sigma}}{\left(p / \delta_{y}\right)^{\chi}+\left(r_{z} / \delta_{s}\right)^{\chi}+\left[\frac{w-\tau_{L}-\tau_{R z}}{\delta_{f}\left(1+t_{z}\right)}\right]^{x}} \\
& T_{F z}^{*}=M_{z} \frac{\left[\frac{w-\tau_{L}-\tau_{R z}}{\delta_{f}^{\rho}\left(1+t_{z}\right)}\right]^{-\sigma}}{\left(p / \delta_{y}\right)^{\chi}+\left(r_{z} / \delta_{s}\right)^{\chi}+\left[\frac{w-\tau_{L}-\tau_{R z}}{\delta_{f}\left(1+t_{z}\right)}\right]^{x}} .
\end{aligned}
$$

Finally, substituting (7), (8) and (9) into the objective function yields the indirect utility as a function of $z$ :

$$
V_{z}^{*}=\left[B+\left(\frac{w-\tau_{L}-\tau_{R z}}{1+t_{z}}\right) T\right]\left[\left(p / \delta_{y}\right)^{\chi}+\left(r_{z} / \delta_{s}\right)^{\chi}+\left[\frac{w-\tau_{L}-\tau_{R z}}{\delta_{f}\left(1+t_{z}\right)}\right]^{\chi}\right]^{-1 / \chi} .
$$

\subsection{Firms}

The competitive, representative firm is located in the CBD and produces a homogenous output, $Q$, under constant returns to scale, with labor as the only input:

$$
Q=A L,
$$

where $A$ denotes the marginal productivity of labor. The zero profit condition restricts the wage to be proportional to the price of the composite good:

$$
w=A p .
$$

\subsection{Road technology and externalities}

Commuting from any given location $z$ to the CBD is taking place through a single radial road, used by all households. Letting $n_{z}$ denote the residential density at location $z$, we can write the travel time per unit of distance at location $z$ as:

$$
t_{0}+t_{1} \int_{z}^{z^{*}} n_{\zeta} D_{W \zeta} d \zeta
$$


i.e. the sum of the free-flow travel time per unit of distance, $t_{0}$, and a term that represents the congestion delay caused by the aggregate traffic volume at $z{ }^{7}$ This flow contains all households that are located between $z$ and the city limit, $z^{*}$, and supply labor equal to the value of the integral in (13). Multiplying this with the sensitivity parameter, $t_{1}$, yields the time delay per unit of distance at point $z$. Integrating (13) over the interval $(0, z)$ yields the commuting time for the household at $z:^{8}$

$$
t_{z}=z t_{0}+t_{1} \int_{0}^{z^{*}} \min \{z, \zeta\} n_{\zeta} D_{W \zeta} d \zeta .
$$

An additional working day supplied from the household at distance $z$ increases the travel time of a commuter located at any $\zeta \geq z$ by $t_{1} z$, and the travel time of each commuter located at $\zeta \leq z$ by $t_{1} \zeta$. This delay can be multiplied by the shadow value of time at $\zeta,\left(w-\tau_{L}-\tau_{R \zeta}\right) /\left(1+t_{\zeta}\right)$, and the total labor supply at $\zeta, n_{\zeta} D_{W \zeta}$, to provide a measure for the marginal external cost of an additional unit of labor imposed by the commuter at $\mathrm{z}$ to the commuter at $\zeta$. Integrating over the interval $\left(0, z^{*}\right)$ yields the marginal external cost of congestion, generated by the household at $z$ :

$$
\operatorname{mecc}(z)=t_{1} \int_{0}^{z^{*}} \min \{z, \zeta\} n_{\zeta} D_{W \zeta}\left(\frac{w-\tau_{L}-\tau_{R \zeta}}{1+t_{\zeta}}\right) d \zeta
$$

\subsection{Public budget}

We assume the existence of a government that imposes road pricing schemes (discussed below) and recycles the labor tax, excess land rents and road toll revenues. The total rent paid by the households is the sum:

$$
R=R_{a}+R_{e}=z^{*} r_{z^{*}}+\int_{0}^{z^{*}}\left(r_{\zeta}-r_{z^{*}}\right) d \zeta
$$

of which the first term, $R_{a}$, is the total cost of renting land from an absentee land owner and the second term, $R_{e}$, is the excess land rent, which is returned to the consumers in a lump-sum manner. This assumption ensures that the city cannot expand without cost, while the excess rents remain within the urban economy. Similarly, the total tax revenue (labor tax revenue, $G_{L}$, plus toll revenue, $G_{R}$ ) collected is:

$$
G=G_{L}+G_{R}=\int_{0}^{z^{*}} n_{\zeta} D_{W \zeta} \tau_{L} d \zeta+\int_{0}^{z^{*}} n_{\zeta} D_{W \zeta} \tau_{R \zeta} d \zeta .
$$

Note that $\tau_{R z}$ is the toll per trip (not per unit of distance) paid by a household located at $z$. In this paper, every toll policy consists of two components: i) a functional form for $\tau_{R z}$, which assigns a unique road

\footnotetext{
7 Therefore, the essence of congestion is captured by assuming that the travel time per unit of distance increases with the number of vehicles passing that point; the linear form is chosen for analytical convenience.

${ }^{8}$ Note that in (13), $z$ refers to a location along the road and $\zeta$ to household locations, while in (14) and (15) $z$ refers to household location.
} 
charge (full trip) to each location $z$, and ii) a description of how $G$ is returned to society. From now on, we are going to refer to those policy components as road toll scheme and revenue recycling respectively. Next, we discuss four road toll schemes and two types of revenue recycling.

\subsubsection{Road toll schemes}

A first possible tolling scheme is the Pigouvian toll, which equates tolls to the marginal external costs of congestion, as defined in (15):

$$
\tau_{R z}=\operatorname{mecc}(z)=t_{1} \int_{0}^{z^{*}} \min \{z, \zeta\} n_{\zeta} D_{W \zeta}\left(\frac{w-\tau_{L}-\tau_{R \zeta}}{1+t_{\zeta}}\right) d \zeta .
$$

The road user located in $z$ therefore pays exactly the marginal external cost she imposes upon the rest of the road users when increasing labor supply by one working day. In absence of other distortions (i.e. when $\tau_{L}=0$ in this model) such a Pigouvian toll constitutes the first-best policy. We assume that the implementation of a Pigouvian toll is perfectly feasible: the government can perfectly monitor commuting activity and households accept the implementation of a sophisticated road toll scheme, such as the one in $(18){ }^{9}$

For $\tau_{L}>0$ the pricing scheme in (18) would no longer be optimal: while the generalized price would then be equal to the marginal costs on the road, the same would not be true for the labor market. The optimal second-best tolling scheme takes this into account. Such a scheme would allow $\tau_{R z}$ to vary in space, but the optimal road charge would deviate from the first-best charge in (18), to account for the distortion in the labor market. We refer to this scheme as a varying-kilometer tax. Practical second-best schemes, however, may have additional constraints. One such scheme we consider is the cordon toll, under which the charging function becomes:

$$
\tau_{R z}=\left\{\begin{array}{cc}
c & \text { if } z \geq \hat{z} \\
0 & \text { otherwise. }
\end{array}\right.
$$

Under cordon pricing, therefore, those located at any distance $z \leq \hat{z}$ face a zero toll and are typically underpriced. The level of charge, $c$, and the location of the toll, $\hat{z}$, determine which shares of those located at $z \geq \hat{z}$ are overpriced and underpriced.

The other scheme we consider involves a flat kilometer tax, with charging function:

$$
\tau_{R z}=\bar{\tau} Z,
$$

where $\bar{\tau}$ is the charge per unit of distance.

\subsubsection{Revenue recycling}

In the absence of a toll, i.e. in the base equilibrium, the lump sum transfer received by each household is:

\footnotetext{
${ }^{9}$ In fact, as it is emphasized in the second-best literature, the cost of attaining this information is very high and the public acceptance of any scheme that exhibits a space variation as the one in (18) may be limited.
} 


$$
B_{0}=\frac{R_{0}+G_{L 0}}{N}
$$

where $N$ denotes the population, $R_{0}$ the excess land rents and $G_{L 0}$ the income tax revenue. ${ }^{10}$ Given the presence of a toll, two cases are considered. In the first, public revenue is returned as a lump-sum transfer (LST). For each household, this is:

$$
B_{1}=\frac{R_{1}+G_{L 1}+G_{R 1}}{N}
$$

Note that the road tax revenue in the base equilibrium is zero, i.e. $G_{R 0}=0$. The alternative scenario involves labor income tax cuts (LTC), such that the tax reform will leave the total tax revenue, $G_{L 1}+G_{R 1}$, unaffected compared to the initial equilibrium, i.e. $G_{L 1}+G_{R 1}=G_{L 0}$. So, this case is associated with lower $\tau_{L}$ compared to the base case.

\subsection{Equilibrium}

In equilibrium, the identical households must be indifferent on where to locate. Thus, the partial derivative of the indirect utility function in (10) with respect to $z$ must be zero. This implies a first order differential equation for the evolution of rent in space:

$$
\begin{aligned}
\frac{d}{d z} r_{z}=r_{z}^{1-\chi}\{ & \left(\frac{\delta_{s}}{\delta_{f}}\right)^{\chi}\left(\frac{w-\tau_{L}-\tau_{R z}}{1+t_{z}}\right)^{\chi-1} D_{z} \\
& \left.-T \delta_{s}^{\chi} D_{z}\left[\left(p / \delta_{y}\right)^{\chi}+\left(r_{z} / \delta_{s}\right)^{\chi}+\left[\frac{w-\tau_{L}-\tau_{R z}}{\delta_{f}\left(1+t_{z}\right)}\right]^{\chi}\right]\right\},
\end{aligned}
$$

with terminal condition:

$$
r_{z^{*}}=r_{A}
$$

where $r_{A}$ is the exogenous agricultural rent and:

$$
D_{z}=-\frac{d}{d z}\left(\frac{w-\tau_{L}-\tau_{R z}}{1+t_{z}}\right)
$$

The aggregate demand for the composite good in the equilibrium is:

$$
Y^{*}=\int_{0}^{z^{*}} n_{\zeta}\left[M_{z} \frac{\left(p / \delta_{y}^{\rho}\right)^{-\sigma}}{\left(p / \delta_{y}\right)^{\chi}+\left(r_{\zeta} / \delta_{s}\right)^{\chi}+\left[\frac{w-\tau_{L}-\tau_{R \zeta}}{\delta_{f}\left(1+t_{\zeta}\right)}\right]^{x}}\right] d \zeta .
$$

\footnotetext{
${ }^{10}$ Although recycling the labor tax revenues in a (non-spatial) lump-sum manner would be a peculiar policy in reality, we choose to model the public budget this way in order to consider the inefficiencies from labor taxation without introducing further inefficiencies from public good provision. The latter would complicate the analysis while being peripheral to what we are interested in: the interactions between labor and transport taxes.
} 
Using (4) and (9) to derive the labor supply, and aggregating over all households yields the aggregate labor supply:

$$
L^{*}=\int_{0}^{z^{*}} n_{\zeta}\left(\frac{1}{1+t_{\zeta}}\right)\left[T-M_{z} \frac{\left[\frac{w-\tau_{L}-\tau_{R \zeta}}{\delta_{f}^{\rho}\left(1+t_{\zeta}\right)}\right]^{-\sigma}}{\left(p / \delta_{y}\right)^{\chi}+\left(r_{\zeta} / \delta_{s}\right)^{\chi}+\left[\frac{w-\tau_{L}-\tau_{R \zeta}}{\delta_{f}\left(1+t_{\zeta}\right)}\right]^{x}}\right] d \zeta .
$$

The assumption of exogenous population, $N$, implies that:

$$
N=\int_{0}^{z^{*}} n_{\zeta} d \zeta .
$$

Finally, the monetary value transferred to the absentee land owner must be equal to the value of the difference between the production and consumption. This condition takes the form:

$$
p\left(Q^{*}-Y^{*}\right)=z^{*} r_{A}
$$

Note that this implies that urban land is, from the city's perspective, purchased at a unit cost, $r_{A}$, while excess land rents (see (16)) are redistributed as in (21). The urban equilibrium is characterized by the vector of endogenous variables $\left(Q^{*}, Y^{*}, G_{L}^{*}, G_{R}^{*}, R^{*}, B^{*}\right)$, the price vector $\left(p^{*}, w^{*}\right)$, the land rent function (solution of (23) and (24)), the travel time as a function of $z$, and the equilibrium city limit, $z^{*}$.

\section{Unimodal framework}

\subsection{Calibration and base equilibrium}

The parameters of the CES utility function $\left(\delta_{y}, \delta_{s}, \delta_{f}, \rho\right)$ and the road technology parameters $\left(t_{0}, t_{1}\right)$, codetermine the level of congestion and a series of endogenous variables and elasticities in the general equilibrium. ${ }^{11}$ These parameters are calibrated ${ }^{12}$ in order for the model to fit a series of stylized facts in the base equilibrium (the initial equilibrium without road pricing). More specifically, the consumption share of income is equal to 0.52 (thus, the expenditure share on rents, mortgages and other types of expenditure related to the residence is equal to 0.48 ). The elasticity of labor supply ranges between 0.26 , close to $\mathrm{CBD}$, and 0.08 , in the city fringe. The median household is characterized by a labor supply elasticity of 0.13 . The parameter $\rho$ gives rise to an elasticity of substitution of (approximately) 0.72 .

Households are working on average $50 \%$ of their disposable time, which translates to an average labor supply of 6 hours per day in the framework of a 12-hour time endowment. This framework excludes a minimum time requirement for sleep and the essential household activities (shopping, child care etc.)

\footnotetext{
${ }^{11}$ We use a Newton-Raphson algorithm combined with optimal step search to compute the equilibrium vector. Existence is not proved analytically; however, a sequence of equilibrium vectors computed for a sequence of convergence criteria indicate it. We have also employed heuristic uniqueness tests involving repeated computations over a set of initial price-quantity vectors.

${ }^{12}$ The base equilibrium parameter vector values are: $\delta_{y}=0.007904, \delta_{s}=0.202399, \delta_{f}=0.031456, \rho=-0.389$, $t_{0}=0.911348 \times 10^{-3}, t_{1}=0.782732 \times 10^{-5}$.
} 
from the full 24-hour day. Since daily labor supply is fixed, the above result can be translated to an annual average labor supply of 182 days. This average encompasses weekends, holidays, sick leaves, part time jobs and temporary unemployment. The commute-to-work time ratio is 0.2 , implying that the average one-way commuting time is 36 minutes. The car speed in the CBD relative to the city fringe is also 0.2 . The free flow travel time parameter, $t_{0}$, suggests that the travel time from the city fringe to CBD for an uncongested road is approximately 0.155. In the same framework of a 12-hour endowment this commuting time is approximately 56 minutes (one-way).

\subsection{Policy analysis}

Table 1 shows the numerical results for the various policy scenarios. These results provide various insights. First, one of the key findings by Parry and Bento is reproduced in our spatial framework. Labor supply is below its social optimum in the base equilibrium, thus policies that return the additional tax revenue in the form of labor tax cuts are at least as good as policies that return all public revenue in the form of a lump sum transfer.

Table 1. The impact of first-best and second-best congestion pricing.

\begin{tabular}{|c|c|c|c|c|c|c|}
\hline $\begin{array}{l}\text { Road toll scheme } \\
\text { Revenue recycling }\end{array}$ & $\begin{array}{l}\text { Base } \\
\text { Lump-sum }\end{array}$ & $\begin{array}{l}\text { Pigouvian } \\
\text { Lump-sum }\end{array}$ & $\begin{array}{l}\text { Naïve } \\
\text { Lump-sum }\end{array}$ & $\begin{array}{l}\text { Varying } \mathrm{km} \text { tax } \\
\text { Tax cuts }\end{array}$ & $\begin{array}{l}\text { Cordon } \\
\text { Tax cuts }\end{array}$ & $\begin{array}{l}\text { Flat km tax } \\
\text { Tax cuts }\end{array}$ \\
\hline \multicolumn{7}{|l|}{ Policy instruments } \\
\hline Labor tax, $\tau_{L}^{*}$ & 0.38 & 0 & 0.38 & 0.2861 & 0.3371 & 0.3085 \\
\hline Charge per $z$ & & as in (18) & as in $(18)$ & see text & & 0.00129 \\
\hline Cordon location, $\hat{z}$ & & & & & $33 \%$ of $z^{*}$ & \\
\hline Cordon charge, $c$ & & & & & 0.09 & \\
\hline \multicolumn{7}{|l|}{ Endogenous variables } \\
\hline$L$ & 494.9 & 542.7 & 483.6 & 497.5 & 496.8 & 497.4 \\
\hline$Y$ & 365.1 & 416.9 & 360.4 & 371.6 & 371.5 & 371.4 \\
\hline$z^{*}$ & 129.8 & 125.8 & 123.2 & 125.9 & 125.3 & 125.8 \\
\hline \multicolumn{7}{|l|}{ Welfare measures } \\
\hline$\omega$ & & 1.0 & & 0.182 & 0.147 & 0.172 \\
\hline$\widehat{\omega}$ & & & & 1.0 & 0.808 & 0.946 \\
\hline CV (annual, $2005 €)$ & & 1230 & -563 & 224 & 181 & 212 \\
\hline
\end{tabular}

Notes: L: aggregate labor supply, Y: aggregate output, $z^{*}$ : city limit, $C V$ : annual compensating variations in $2005 €, \omega$ : relative efficiency (benchmark: first best), $\widehat{\omega}$ : relative efficiency (benchmark: varying kilometer tax).

Assuming tolls should be non-negative, the cordon-lump sum (CoLST) and the flat kilometer taxlump sum ( FkmLST) cannot increase welfare compared to the base equilibrium. The reason is that the preexisting labor tax is so high that any increase in road taxes aggravates distortions, that outweigh any gains from congestion reduction. Therefore, these schemes reproduce the base equilibrium and are omitted in Table 1 and all relevant figures. On the other hand, if revenues are recycled through labor tax cuts 
(CoLTC and FktLTC respectively) there are efficiency gains. The equilibrium values of the policy instruments and endogenous variables associated with these policies are provided in the last two columns of Table 1 .

The efficiency gains of the discussed policies are computed relative to the efficiency gains of two benchmark policies. The first one involves a complete elimination of the labor tax and the introduction of a Pigouvian toll (see the charging function in (18)) to commuters, with all revenue returned as a lump sum transfer. In this hypothetical first-best scenario, the road tax varies optimally over space. We can denote by $C V_{1}^{*}$ the (general equilibrium) compensating variation ${ }^{13}$ under this scenario $\left(\tau_{R z}\right.$ as in $(18)$ and $\left.\tau_{L}=0\right)$ relative to the base scenario $\left(\tau_{R z}=0\right.$ and $\left.\tau_{L}=0.38\right)$; and by $C V_{2}^{*}$ the respective compensating variation under any second-best scenario. Then, the relative efficiency of an arbitrary second-best policy can be expressed as $\omega=C V_{2}^{*} / C V_{1}^{*}$. The revenues of the cordon toll allow the labor tax to drop from 0.38 to 0.337 and yield a relative efficiency gain of $14.7 \%$. In line with this result, a flat kilometer tax reduces the labor tax to 0.309 with a relative efficiency gain of $17.2 \%$. Hence, both policies obtain almost identical gains in this context.

One may argue that $\omega$ is not a very relevant indicator of efficiency, as $V_{1}^{*}$ refers to a case in which tax revenue, $G$, is allowed to be much lower than its base level. ${ }^{14}$ In reality, $G$ could be justified by the need to provide public goods (or other functions of a federal or local government) that are not modeled explicitly in this paper. Therefore, it is useful to replace the denominator of $\omega$ with a measure of the maximum welfare gain that can be realized, given that tax revenue should remain constant. This second benchmark policy combines a varying kilometer tax, $\tau_{R z}$, with a labor tax, $\tau_{L}$, such that, in equilibrium, $G$ will not differ from its base level. Denoting the compensating variation of this marginal tax reform with $C V_{1 G}^{*}$, we define a new measure of relative efficiency: $\widehat{\omega}=C V_{2}^{*} / C V_{1 G}^{*}$.

The optimum for this benchmark policy can be found numerically. One way to obtain a value for $C V_{1 G}^{*}$ is to approximate the optimal varying kilometer tax with a $n$-th degree polynomial. That is, the entire road interval $\left(0, z^{*}\right)$ from the CBD to the city fringe can be divided in $n$ road segments. The optimal road charge can then be computed in each of the $n+1$ points ${ }^{15}$ that separate these segments, and Lagrangian interpolation is used to provide the road charge for every arbitrary location $z$. The associated labor tax with this policy turns out to be 0.286 . The compensating variation of this policy can be used as an appropriate value of $C V_{1 G}^{*}$ to derive $\widehat{\omega}$ for the cordon toll and the flat kilometer tax with revenues recycled as labor tax cuts. The results suggest that both of them perform very satisfactory by capturing respectively $80.8 \%$ and $94.6 \%$ of the monetized gains of the optimal varying kilometer tax.

The second insight concerns the profile of the optimal total tax (i.e. labor and road tax added) under a varying kilometer tax, shown as one of the curves in the upper left panel of Figure 1. This function can be decomposed into three different components: i) a uniform labor tax, ii) a road tax equal to the marginal external cost of congestion, and iii) a Ramsey-Mirrlees component that reflects the constraints under which the optimal values of policy instruments have been computed.

\footnotetext{
${ }^{13}$ Define this welfare measure as the amount of money that needs to be taken from (given to) each household after the implementation of the policy, in the equilibrium price vector $\mathbf{p}^{1}$ in order to reach a new equilibrium with price vector $\mathbf{p}^{2}$ and utility level equal to this of the base equilibrium (with price vector $\mathbf{p}^{0}$ ).

${ }^{14}$ Note that $G=188.07$ in the base equilibrium and only 48.81 in the first-best equilibrium.

${ }^{15}$ We have used a division of the road interval $\left(0, z^{*}\right)$ in five segments of equal length. Letting the vector $\boldsymbol{\delta}$ denote the distance of those points from CBD as percentages of the total distance between the CBD and the city limit, $z^{*}$, the vector $z^{*} \boldsymbol{\delta}^{\prime}$ expresses the exact location of each selected point in the sequence. In the present paper we choose $\boldsymbol{\delta}^{\prime}=(0,0.2,0.4,0.6,0.8,1.0)$. For the equilibrium city size, $z^{*}=125.9$, these locations are given by $z^{*} \boldsymbol{\delta}^{\prime}=(0$, $25.18,50.36,75.54,100.72,125.9)$.
} 
The latter component consists of two parts. The Ramsey part refers directly to the labor market, and implies that the tax should be higher where labor supply is less elastic. Since the elasticity of labor supply decreases with distance from the CBD, this part implies a strictly increasing (in $z$ ) tax. The Mirlees part refers to the fact that marginal utility of income rises with distance from the CBD. Because all households receive the same labor tax cut, the road tax will adjust to partially correct this inefficient treatment (Wildasin, 1986). The two components work in opposite direction, thus the combined effect can portray a complex, even non-monotonic pattern over space. It can be shown that, in certain cases, a negative combined effect can be large enough to give rise to a negative local road tax (van Dender, 2004). Otherwise, Figure 1 summarizes rent, labor supply and the spatial allocation of the compensating variation $^{16}$ of each policy discussed above as a function of distance from the CBD.

Fig. 1. Total tax per unit of supplied labor, rent, labor supply and compensating variations.
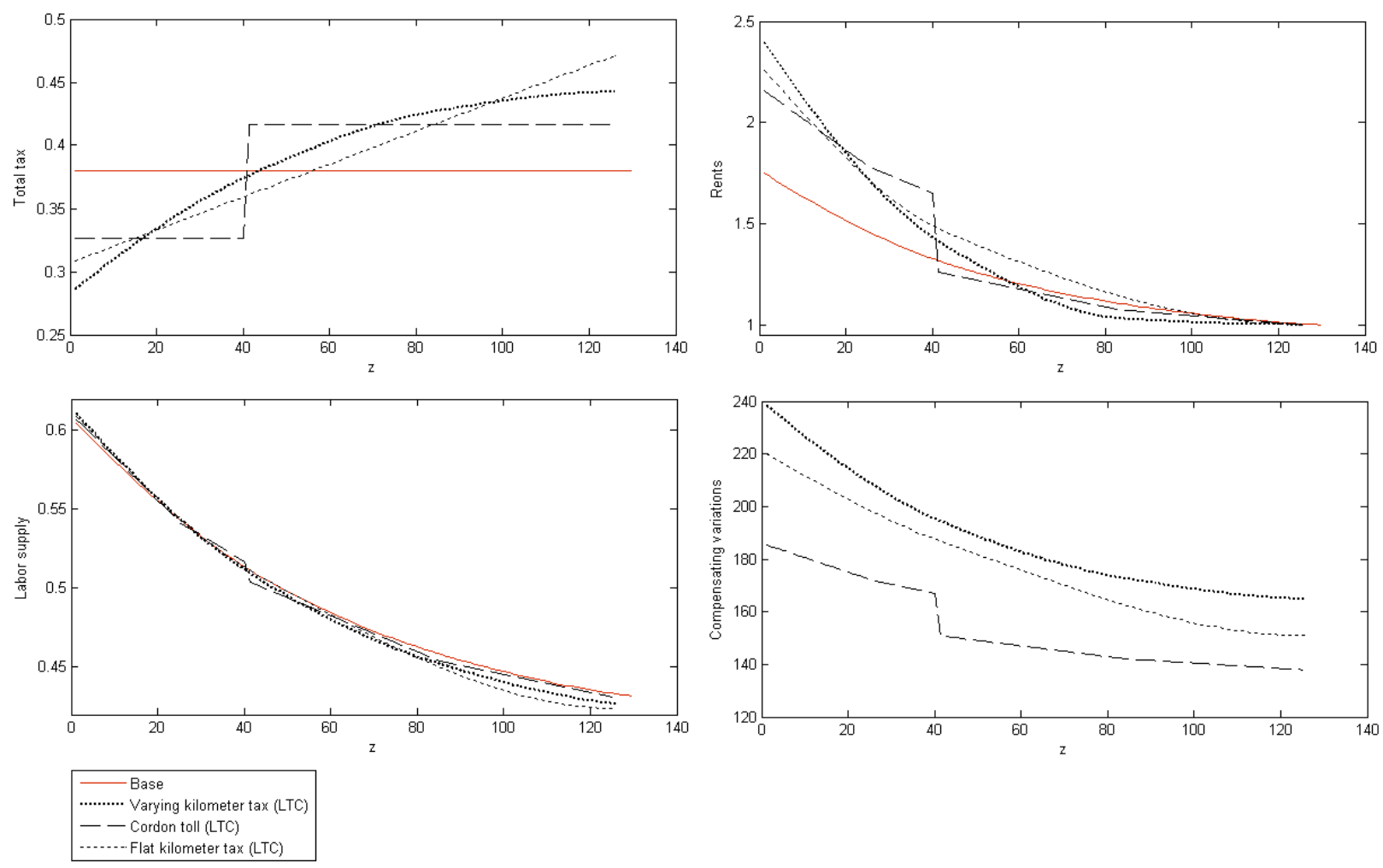

The third insight regards the welfare effects of a space-varying tax in the absence of congestion. A natural way to acquire a measure over the magnitude of the Ramsey-Mirrlees component is to compare its space variation to this of the total road tax. This expresses how much of the total tax is dedicated to purposes that are not directly related to congestion. The upper left panel of Figure 2 indicates that this is approximately $35 \%$ of the total road tax, implying that a space-varying road tax might be welfare improving even without congestion. In fact, as the upper right panel of Figure 2 suggests, in absence of congestion the component retains most of its spatial variation, although road externalities disappear

${ }^{16}$ The CV measures in the lower right panel of Figure 1 vary due to the fact that marginal utility of income varies over space. They express the sum of money that should be taken (after the implementation of a policy) from the household at distance $z$ in order to reach the utility level of the base equilibrium, keeping all prices constant. 
completely. The middle and lower panels of the same figure show the corresponding elasticity of labor supply (with respect to the labor tax) and the marginal utility of income respectively. In both cases, the combined effect implies that the Ramsey-Mirrlees component should be increasing with distance, suggesting that it is mainly a labor tax correction over space.

Fig. 2. Marginal external cost of congestion and the Ramsey-Mirrlees (RM) component (upper panel), labor supply elasticity (middle panel) and the marginal utility of income (lower panel) across space.
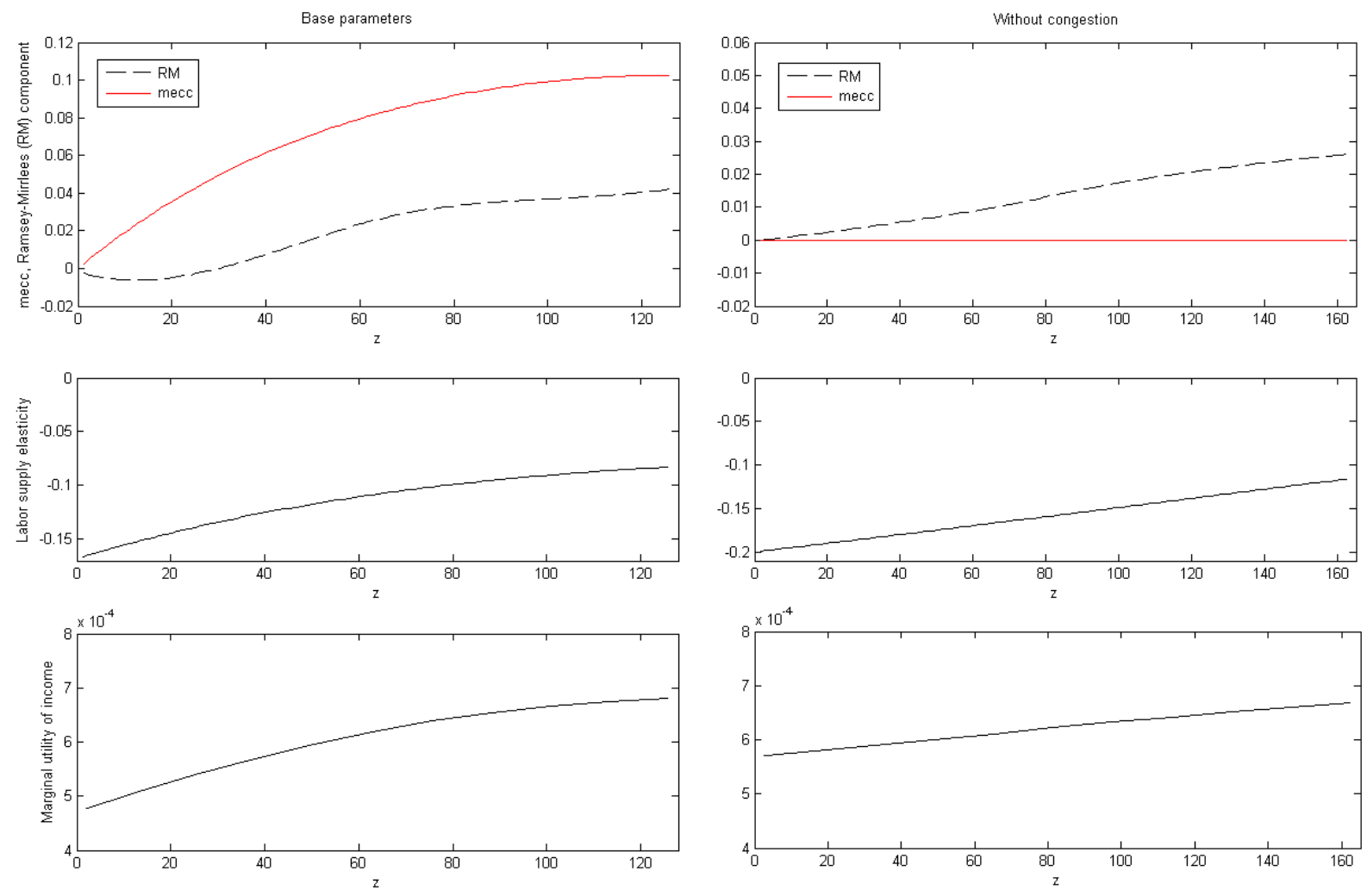

The last line of Table 1 provides the monetized benefits of each policy in terms of compensating variations, $\mathrm{CV}$, i.e. the amount of money that the representative household has to forego (after the implementation of each policy) in order to return to the utility level of the base equilibrium. This measure is positive in all equilibria apart from the naive equilibrium (discussed below), in which welfare is decreased. These values have been computed under the assumption that the representative household has a disposable income of $52000 €$ (the 2005 average in the Netherlands). ${ }^{17}$

Finally, we consider the so called naive equilibrium, i.e. the equilibrium that prevails when the marginal external cost of congestion (see equation (18)) is charged on top of the base labor tax of 0.38 , and the revenues are returned as lump-sum. Partial equilibrium, or even general equilibrium models which disregard distortionary taxes, would predict that such policies increase, or even maximize welfare.

\footnotetext{
${ }^{17}$ Dividing the model's CV values by $(w L) / N$ yields the monetary gain of each policy per unit of money earned by the representative household. Multiplying this gain with the average disposable income of a Dutch household (approximately $52000 €$ in 2005 values) yields the monetized gains predicted by the model, if the income is equal to that in the Netherlands.
} 
Our results show that such policies can lead to very inefficient outcomes: the monetized extra burden of the toll in the context of this model is about 563 euro per year.

\subsection{Sensitivity analysis}

To investigate whether the relative welfare gains, $\widehat{\omega}$, are robust to the chosen parameters we perform oneway sensitivity analyses with respect to the base labor tax rate, $\tau_{L}$, and the elasticity of substitution, $\sigma$. Figure 3 summarizes the findings from computations with different levels of the initial elasticity of substitution and the labor income tax. We set the range of the tax rate between 0.30 and 0.45 to account for the fact that the majority of workers in Western Europe and North America face a labor tax within this range. We set $\sigma$ to vary between 0.58 and 0.90 .

The right panel of Figure 3 suggests that the results on relative efficiency are very robust across the range of $\sigma$-values which give rise to a significant variation in the consumption share of income, which ranges between 0.58 and 0.43 , and in the elasticity of labor supply, which for the median household varies between 0.10 and 0.17 .

Fig. 3. Sensitivity analysis of the relative efficiency, $\widehat{\omega}$, with respect to $\sigma$ and $\tau_{L}$.
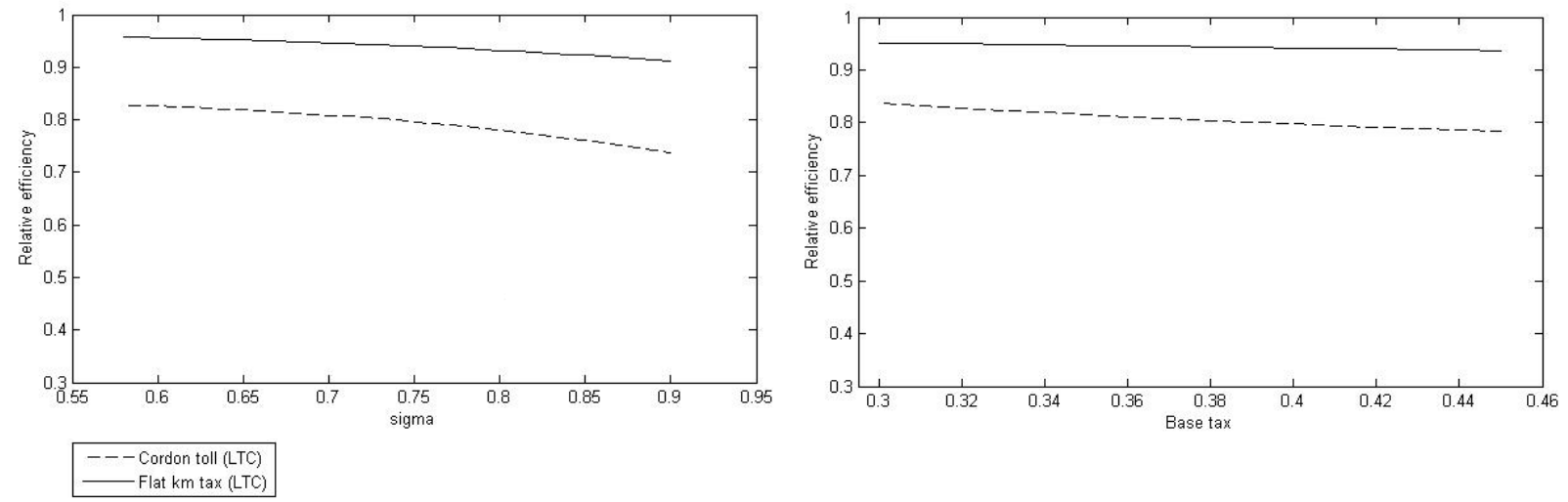

- Cordon toll (LTC)

The qualitative results of the sensitivity analysis with respect to the labor tax (right panel of Figure 3) indicate that this robustness is even stronger. This can be attributed to the corresponding variation of the key stylized facts, which is smaller across the different values of $\tau_{L}$. The consumption share of income ranges between 0.54 and 0.49 , and the elasticity of labor supply of the median household varies between 0.11 and 0.15 .

The sensitivity analysis with respect to road technology parameters $t_{0}$ and $t_{1}$ is summarized in Figure 4. For each computation, the base values of $t_{0}$ and $t_{1}$ have been multiplied with scalars from the interval $[0.6,1.4]$. To interpret the results of Figure 4 , one should take into account that as $t_{0}$ and $t_{1}$ decrease, the relative contribution of the Ramsey-Mirrlees component to the total road tax increases. Subsequently, due to the nature of this element, which tends to be more complex than the marginal external congestion cost, the archetype pricing schemes capture a smaller part of the efficiency gain that can be generated by a varying kilometer tax. The foregone relative efficiency is bigger in the case of the cordon toll, which is far from the ideal tax instrument for dealing with the Ramsey-Mirrlees component. 
However, this sensitivity is moderate, when considering the impact of altering these parameters on the prevailing equilibrium. ${ }^{18}$

Fig. 4. Sensitivity analysis of the relative efficiency, $\widehat{\omega}$, with respect to the road technology parameters $t_{0}$ and $t_{1}$. Left panel: cordon toll-labor tax cuts. Right panel: flat kilometer tax-labor tax cuts.
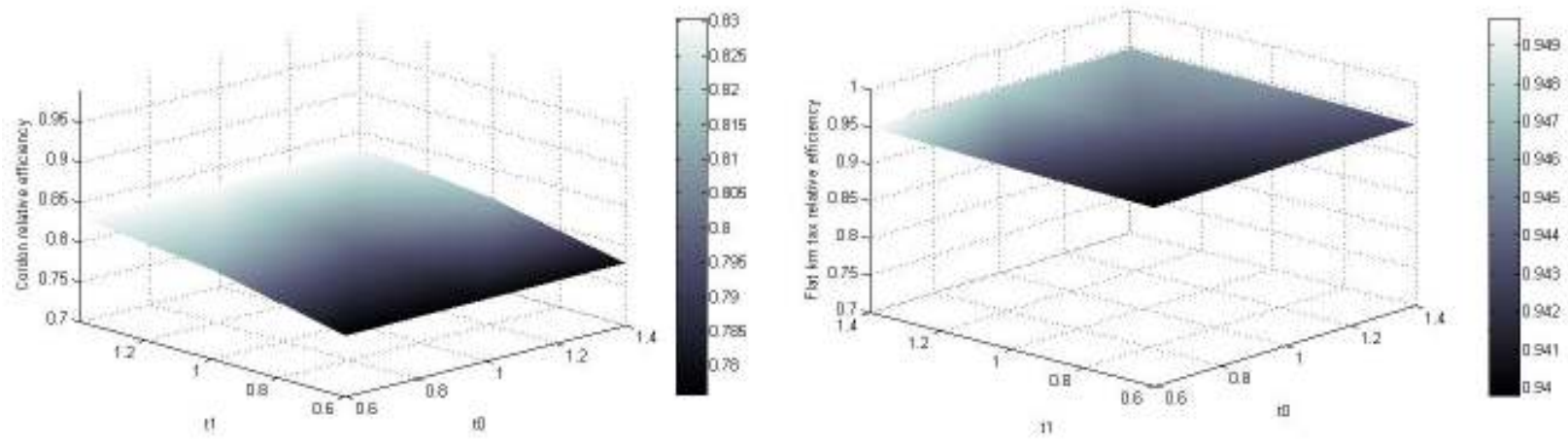

\section{Bimodal framework}

In this section we expand the model to account for the existence of a mass transit provider which, in the base equilibrium, operates with fixed costs and average cost pricing. We subsequently juxtapose policies which return the road tax revenue in the form of labor tax cuts against policies which use this revenue to subsidize the public transport provider. It is shown that the optimal policy depends heavily on the size of fixed costs in public transport.

\subsection{Expanded model}

Now let the same household choose between commuting with car or public transport. Then, the demand functions in (7), (8), (9) and the indirect utility in (10) are not only conditional to the commuting distance, $z$, but are also mode-specific, representing the car mode. If the household chooses public transport, its time constraint will be:

$$
d_{W Z}^{P}=\frac{T-T_{F Z}^{P}}{1+t_{z}^{P}}
$$

where the superscript $P$ denotes the choice of the public mode. Similarly, the conditional budget constraint will be:

$$
B+\frac{\left(w-\tau_{L}-p_{P Z}\right)}{1+t_{z}^{P}} T=\frac{\left(w-\tau_{L}-p_{P z}\right)}{1+t_{z}^{P}} l_{z}+p y_{z}^{P}+r_{z} s_{z}^{P}
$$

\footnotetext{
${ }^{18}$ For instance, when both parameters are set to $60 \%$ of their initial value, the average commute-to-work ratio falls by $30 \%$ and the marginal external cost of congestion caused by the most remote household reduces by $25 \%$.
} 
where $p_{P z}$ denotes the ticket fare from $z$ to the CBD and $t_{z}^{P}$ the respective commuting time. The Marshallian demand functions for the composite good, space and leisure time, and the indirect utility function are respectively:

$$
\begin{aligned}
& y_{z}^{P *}=M_{z}^{P} \frac{\left(p / \delta_{y}^{\rho}\right)^{-\sigma}}{\left(p / \delta_{y}\right)^{\chi}+\left(r_{z} / \delta_{s}\right)^{\chi}+\left[\frac{w-\tau_{L}-p_{P z}}{\delta_{f}\left(1+t_{z}^{P}\right)}\right]^{\chi}}, \\
& S_{z}^{P *}=M_{z}^{P} \frac{\left(r_{z} / \delta_{s}^{\rho}\right)^{-\sigma}}{\left(p / \delta_{y}\right)^{\chi}+\left(r_{z} / \delta_{s}\right)^{\chi}+\left[\frac{w-\tau_{L}-p_{P z}}{\delta_{f}\left(1+t_{z}^{P}\right)}\right]^{\chi}}, \\
& T_{F z}^{P *}=M_{z}^{P} \frac{\left[\frac{w-\tau_{L}-p_{P z}}{\delta_{f}^{\rho}\left(1+t_{z}^{P}\right)}\right]^{-\sigma}}{\left(p / \delta_{y}\right)^{\chi}+\left(r_{z} / \delta_{s}\right)^{\chi}+\left[\frac{w-\tau_{L}-p_{P z}}{\delta_{f}\left(1+t_{z}^{P}\right)}\right]^{\chi}}, \\
& V_{z}^{P *}=\left[B+\left(\frac{w-\tau_{L}-p_{P z}}{1+t_{z}^{P}}\right) T\right]\left[\left(p / \delta_{y}\right)^{\chi}+\left(r_{z} / \delta_{s}\right)^{\chi}+\left[\frac{w-\tau_{L}-p_{P z}}{\delta_{f}\left(1+t_{z}^{P}\right)}\right]^{\chi}\right]^{-1 / \chi}
\end{aligned}
$$

The indirect utility functions in (10) and (35) are the systematic utilities for the choice of car and public transport respectively. To prevent cases in which residents choose exclusively car in some areas and public transport in others, a stochastic term, $\varepsilon_{n m}$, which is i.i.d. extreme value type I across households (denoted by the subscript $n$ ) and transport modes (denoted by the subscript $m$ ) is added to these functions. The stochastic term captures daily variations in the household preferences regarding the commuting mode. This assumption implies that the same household will some days commute by car and some others using the public transport mode, with a logit choice probability. Letting $y_{Z}^{C *}, s_{Z}^{C *}, T_{F Z}^{C *}$ and $V_{Z}^{C *}$ denote the respective demand functions and the systematic utility when choosing car, the logit choice probability for car is:

$$
\operatorname{Pr}^{C}=\frac{\exp \left(V_{z}^{C *}\right)}{\exp \left(V_{z}^{C *}\right)+\exp \left(V_{z}^{P *}\right)}
$$

Furthermore, it can be shown (Small and Rosen, 1981) that the expected maximum utility in this choice situation (car versus public transport mode given the commuting distance $z$ ) is:

$$
E\left[\max \left\{V_{z}^{C *}+\varepsilon^{C}, V_{z}^{P^{*}}+\varepsilon^{P}\right\}\right]=\ln \left\{\exp \left(V_{z}^{C *}\right)+\exp \left(V_{z}^{P *}\right)\right\}
$$

In equilibrium, the derivative of (37) with respect to the land rent, $r_{z}$, should be equal to zero. The expected equilibrium consumption and labor supply are calculated as probability-weighted sums of the conditional expressions given above.

We assume that the public transit operator that produces passenger kilometers, $q$, is subject to a cost function: 


$$
C(q)=F+\varphi_{0} q+\varphi_{1} q^{2}
$$

In equilibrium, the degree of scale economies, defined as the ratio of average to marginal cost, is:

$$
s(q)=\frac{A C(q)}{M C(q)}=\frac{(F / q)+\varphi_{0}+\varphi_{1} q}{\varphi_{0}+2 \varphi_{1} q} .
$$

The operator incurs the fixed cost $F$, which might include construction, maintenance and organization, and which might lie in a wide range, depending on the mode and the idiosyncratic characteristics of the city and its transport system. We ignore congestion effects in public transport, as for example in Basso and Jara-Díaz (2012). Therefore, the commuting time with the public mode is simply proportional to distance:

$$
t_{z}^{P}=t_{2} z
$$

where the technology parameter $t_{2}$ denotes the travel time per unit of distance.

The operator is assumed to run a balanced budget, as for example in Japan (Priemus and Konings, 2001), so the public transport kilometer price is equal to the average cost, i.e. $p_{P}(q)=(F / q)+\varphi_{0}+\varphi_{1} q$. This introduces an inefficiency in the transport market, since the resulting price deviates from the marginal social cost of a passenger kilometer. However, the revenue of the road toll can be used to subsidize the operator, rather than to reduce the income tax. In this case the resulting price is: $p_{P}(q)=\left(\left(F-G_{R}\right) / q\right)+\varphi_{0}+\varphi_{1} q$. With this policy intervention, a part of the inefficiency in the transport market is restored, but the labor market benefit will be smaller, compared to the case of labor tax cuts. The only changes that occur stem from labor supply change due to cheaper public transport. The purpose of the next section is to compare the welfare implications of these two revenue recycling programs.

\subsection{Results}

In order to calibrate the parameters of the extended model we have assumed that, in the base equilibrium of the bimodal framework, $1 \%$ of the city's output is used to pay for the fixed costs of public transport. This number is only speculative; a sensitivity analysis in a substantial range around this level follows below. The public transit technology parameter, $t_{2}$, is set to 0.003 . This implies that the speed of the public mode is $30 \%$ of the car speed on the freeway. The parameters of the public transit cost function are such that, in the base equilibrium, $s(q)$ in (39) is equal to 1.4 and $s(2 q)$ is equal to 1 . We therefore initiate our sensitivity analysis from a base equilibrium characterized by significant economies of scale and a level of output (passenger kilometers) which lies halfway to its break-even level. ${ }^{19}$ Otherwise, the equilibrium stylized facts (consumption share of expenditure, CBD-to-fringe speed ratio, labor supply elasticity, commute-to-work time ratio) resemble those reported in the unimodal case. ${ }^{20}$

Figure 5 summarizes the results of sensitivity analysis with respect to the level of fixed costs, $F$. The figure shows the welfare gain from using the revenues for labor tax cuts relative to using it for public transport subsidies, when the pricing scheme is the cordon toll (dashed line) or the flat kilometer tax (solid line). Each point on the horizontal axis represents an initial equilibrium, in which a different

\footnotetext{
${ }^{19}$ Bimodal base equilibrium: $F=5.097, \varphi_{0}=0.583 \times 10^{-3}, \varphi_{1}=0.8827 \times 10^{-8}$.

${ }^{20}$ Consumption share: 0.50 , commute-to-work ratio: 0.134 , labor supply elasticity: 0.154 , CBD-to-fringe speed ratio: 0.2 .
} 
fraction of the city's total output, $Y$, is directed to cover the transport system's fixed costs, $F$, while the rest of the parameters in the model are fixed. Thus, the extent of scale economies, $s(q)$, varies significantly across the range of fixed costs $(0-2 \%$ of total output); from approximately 0.87 when $F$ is close to zero, to 1.8 when $F$ is $2 \%$ of the output value. ${ }^{21}$ For the equilibria within this range, we report the relative compensating variations of the two archetype schemes, i.e. the compensating variations of a cordon toll combined with labor tax cuts over the compensating variations generated by a cordon toll combined with public transport subsidies (CoLTC over CoPTS in the dashed line) and the respective fraction for the case of a flat kilometer tax (FktLTC over FktPTS in the solid line).

Fig. 5. Compensating variations generated by labor tax cuts expressed relative to those generated by public transport subsidies.

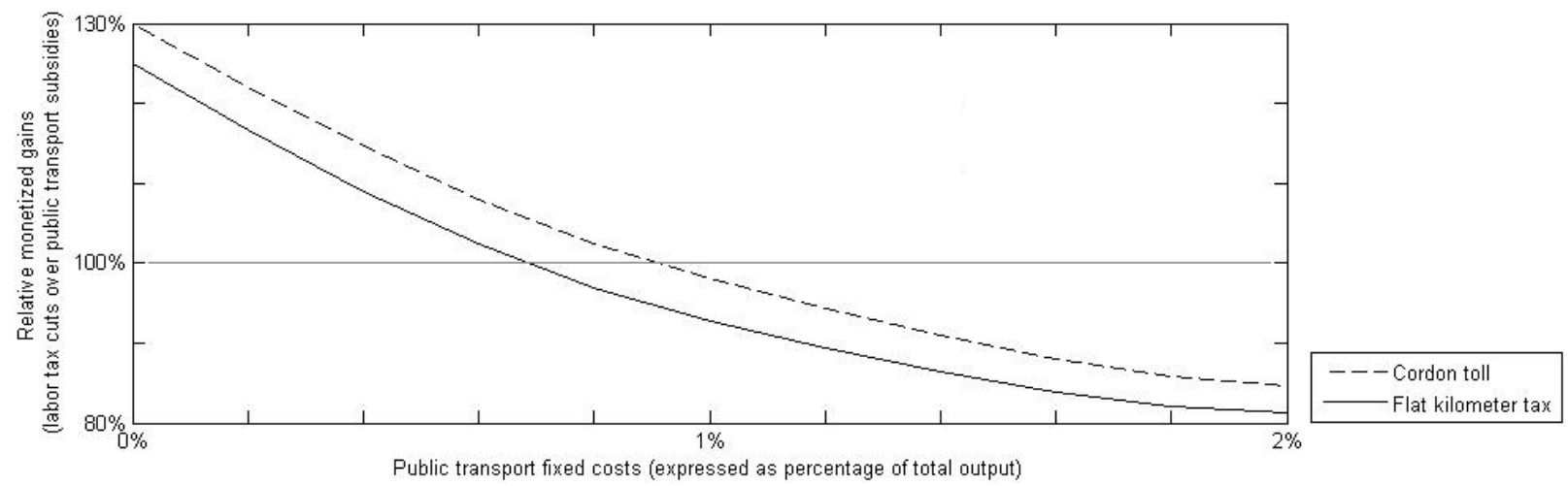

As the fixed costs of public transport decrease, the gains from policies that return the revenue from the toll road in the form of a subsidy to the operator (CoPTS, FktPTS) decrease relative to the gains generated by policies which reduce the labor tax (CoLTC, FktLTC). The reason is that with lower fixed costs, the public transport provider operates much closer to the break-even point and average cost pricing is much closer to the (optimal) marginal cost pricing. Thus, the marginal social benefit of spending one euro in the labor market (through a decrease in the labor tax) is much higher than the respective marginal benefit of using one euro to subsidize the public transport operator. The opposite holds for high values of $F$. Therefore, this paper advocates for revenue recycling strategies that complement those by Parry and Bento (2001), who exclude public transport fixed costs from their model and derive a policy recommendation which universally rejects public transport subsidies in favor of labor tax cuts. Contrary to this, our results indicate a threshold value of fixed costs, above which public transport subsidies become the most efficient form of revenue recycling in a monocentric city. This threshold value lies between 0.6 and $1.0 \%$ of the total output, but it might lie lower in a model that accounts for the environmental externalities generated by the use of private modes. ${ }^{22}$

21 This range of scale economies is roughly consistent with the empirical findings by Viton (1981).

22 If we assume subsidies affect mode choice, as it would be the case under average cost pricing in public transport. 


\section{Concluding remarks}

This paper studies the role of space-varying taxes and revenue recycling programs in monocentric frameworks with a distorted labor market. We show that, with a preexisting labor tax and congestion externalities, only a part of the optimal space-varying tax corresponds to road externalities. For our numerical example, this is approximately $65 \%$. The remaining 35\% concerns the Ramsey-Mirrlees component, that aims to achieve two objectives. The Ramsey part of the component aims to minimize the social cost of raising a given tax revenue by setting taxes higher where labor supply is less elastic. The Mirrlees part aims to set taxes lower where the marginal utility of monetary income is higher. Since the former and latter imply a tax that, respectively, increases and decreases with distance from CBD, the joint effect can portray a complex, even non-monotonic pattern over space. The Ramsey-Mirrlees component retains its spatial profile when road externalities diminish, advocating in favor of a space-varying tax even in contexts without traffic congestion.

The sign of a policy's welfare effect depends strongly on the revenue recycling program it contemplates. In the numerical model, the usual textbook prescription of a Pigouvian toll (on top of the labor tax) with revenue returned in a lump sum manner, causes annual welfare losses of about $560 €$ per household. In contrast, a varying kilometer charge which uses the road toll revenues to reduce the preexisting labor tax generates annual welfare gains of about $225 €$ per household. Intuitively, this marginal tax reform -all revenue from road pricing is used to finance labor tax cuts- generates a weak double dividend (Goulder, 1995b; Bovenberg, 1999) by working in two directions; it reduces the congestion externalities by making commuting more expensive and, simultaneously, it increases labor supply by lowering the distortionary labor tax. These results accord, from a qualitative point of view, with those by Parry and Bento, but our model shows that these gains and losses are strongly differentiated across space.

While revenue recycling is crucial in order to generate efficiency gains rather than losses, the magnitude of the potential gains also depends on the implemented road toll scheme. Our computations suggest that, with revenues returned as labor tax cuts, both archetype schemes (the cordon toll and the flat kilometer tax) perform very well, capturing a large part ( $81 \%$ and $95 \%$ respectively) of the maximum gains that can be generated by a varying kilometer tax. The ability of these schemes to capture the welfare gains of more complex pricing schemes and the relative supremacy of the flat kilometer tax over the cordon toll are in accordance with earlier findings (Verhoef, 2005) which abstract from distortions in the labor market. Therefore, it is shown that these previous findings are robust when someone considers marginal tax reforms involving markets outside the transport system.

In order to juxtapose labor tax cuts against public transport subsidies, we have also considered a bimodal setting with choice between car and a public transport. Assuming fixed costs and average cost pricing in the provision of public transport, we find that public transport subsidies may be superior to labor tax cuts, beyond a certain level of fixed costs in the supply of public transport. Therefore, this paper advocates for revenue recycling strategies that complement those by Parry and Bento (2001), who exclude public transport fixed costs from their model and, subsequently, universally reject public transport subsidies in favor of labor tax cuts.

This paper modifies the monocentric model to account for road externalities, labor market distortions and non-marginal cost pricing in public transport. However, a series of other relevant distortions have been ignored and deserve attention in future work. These include rent controls and regulations that affect the urban density (e.g. restrictions in building height or the city boundary). 
Furthermore, we have exclusively focused on a monocentric city. The investigation of marginal tax reforms which combine land and labor taxation with road tolls in a polycentric setting is left as a topic for future research.

\section{Acknowledgements}

We would like to thank participants in the 6th Kuhmo-Nectar conference in Berlin, July 2012, and in the Urban Economics session of the NARSC conference in Ottawa, November 2012. Also, the attendants of the seminar in Tinbergen Institute and the meetings of i-PriSM project. We are indebted to the Netherlands Organization for Scientific Research (NWO) for the financial support.

\section{References}

Basso, L.J. \& Jara-Díaz, S.R. 2012. Integrating congestion pricing, transit subsidies and mode choice. Transportation Research Part A, 46, 890-900.

Bovenberg, A.L. 1999. Green tax reforms and the double dividend: an updated reader's guide. International Tax and Public Finance, 6, 421-443.

Brueckner, J.K., Thisse, J.F., Zenou, Y. 1999. Why is central Paris rich and downtown Detroit poor? An amenity-based theory. European Economic Review, 43, 91-107.

Calthrop, E., Proost, S., van Dender, K. 2000. Parking policies and road pricing. Urban studies, 37, (1) 63-76.

De Borger, B. 2009. Commuting, congestion tolls and the structure of the labour market: optimal congestion pricing in a wage bargaining model. Regional Science and Urban Economics, 39, 434448.

Glaeser, E.L., Luttmer, E.F.P. 2003. The misallocation of housing under rent control. American Economic Review, 93, 1027-1046.

Goulder, L.H. 1995a. Effects of carbon taxes in an economy with prior tax distortions: an intertemporal general equilibrium analysis. Journal of Environmental Economics and Management, 29, 271297.

Goulder, L.H. 1995b. Environmental taxation and the double dividend: a reader's guide. International Tax and Public Finance, 2, 157-183.

Langmyhr, T. 1997. Managing equity. The case of road pricing. Transport Policy, 4, (1) 25-39.

Mayeres, I., Proost, S. 2001. Marginal tax reform, externalities and income distribution. Journal of Public Economics, 79, 343-363.

Mun, S., Konishi, K., Yoshikawa, K. 2003. Optimal cordon pricing. Journal of Urban Economics, 54, 2138.

Mun, S., Konishi, K., Yoshikawa, K. 2005. Optimal cordon pricing in a non-monocentric city. Transportation Research Part A, 39, 723-736.

Parry, I. 2002. Comparing the efficiency of alternative policies for reducing traffic congestion. Journal of Public Economics, 85, 333-362.

Parry, I., Bento, A. 2001. Revenue recycling and the welfare effects of road pricing. Scandinavian Journal of Economics, 103, (4) 645-671.

Parry, I., Bento, A. 2002. Estimating the welfare effects of congestion taxes: the critical importance of other distortions within the transport system. Journal of Urban Economics, 51, 339-365.

Priemus, H., Konings, R. 2001. Light rail in urban regions: what Dutch policymakers could learn from experiences in France, Germany and Japan. Journal of Transport Geography, 9, 187-198. 
Ramjerdi, F., Østmoe, K., Minken, H. 2008, Experience with measuring equity and efficiency: a case $\mathrm{f}$ rom Oslo, in: Road pricing, the Economy and the Environment, C. Jensen-Butler et al., eds., Springer.

Small, K.A., Rosen, H.S. 1981. Applied welfare economics with discrete choice models. Econometrica, 49, (1) 105-130.

Small, K.A., Yan, J. 2001. The value of "value pricing" for roads: second-best pricing and product differentiation. Journal of Urban Economics, 49, 310-336.

Sullivan, A.M. 1983. Second best policies for congestion externalities. Journal of Urban Economics, 14, 105-123.

van Dender, K. 2004. Pricing transport networks with fixed residential location. Regional Science and Urban Economics, 34, 289-307.

Verhoef, E. 2005. Second-best congestion pricing schemes in the monocentric city. Journal of Urban Economics, 58, 367-388.

Verhoef, E., Nijkamp, P., Rietveld, P. 1996. Second best congestion pricing: the case of an untolled alternative. Journal of Urban Economics, 40, 279-302.

Viton, P.A. 1981. A Translog Cost Function for Urban Bus Transit. The Journal of Industrial Economics, 29, (3) 287-304.

Wildasin, D. 1986. Spatial variation of the marginal utility of income and unequal treatment of equals. Journal of Urban Economics, 19, 125-129. 